
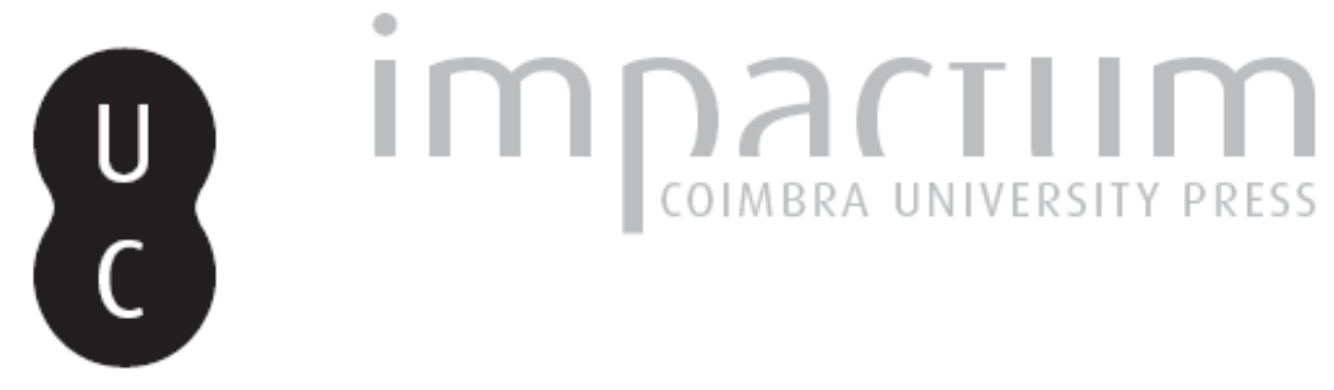

\title{
Breve nota de leitura sobre Álcman
}

Autor(es): $\quad$ Lourenço, Frederico

Publicado por: $\begin{aligned} & \text { Associação Portuguesa de Estudos Clássicos; Instituto de Estudos } \\ & \text { Clássicos }\end{aligned}$

URL persistente:

URI:http://hdl.handle.net/10316.2/30374

DOI:

DOI:http://dx.doi.org/10.14195/0872-2110_52_1

Accessed : $\quad$ 26-Apr-2023 11:46:01

A navegação consulta e descarregamento dos títulos inseridos nas Bibliotecas Digitais UC Digitalis, UC Pombalina e UC Impactum, pressupõem a aceitação plena e sem reservas dos Termos e Condições de Uso destas Bibliotecas Digitais, disponíveis em https://digitalis.uc.pt/pt-pt/termos.

Conforme exposto nos referidos Termos e Condições de Uso, o descarregamento de títulos de acesso restrito requer uma licença válida de autorização devendo o utilizador aceder ao(s) documento(s) a partir de um endereço de IP da instituição detentora da supramencionada licença.

Ao utilizador é apenas permitido o descarregamento para uso pessoal, pelo que o emprego do(s) título(s) descarregado(s) para outro fim, designadamente comercial, carece de autorização do respetivo autor ou editor da obra.

Na medida em que todas as obras da UC Digitalis se encontram protegidas pelo Código do Direito de Autor e Direitos Conexos e demais legislação aplicável, toda a cópia, parcial ou total, deste documento, nos casos em que é legalmente admitida, deverá conter ou fazer-se acompanhar por este aviso.

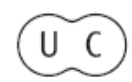




\section{Boletim de}

\section{Estudos Clássicos}

Associação Portuguesa de Estudos Clássicos Instituto de Estudos Clássicos

Coimbra

Dezembro de 2009 


\section{BREVE NOTA DE LEITURA SOBRE ÁlCMAN}

\section{O Poeta}

Se Álcman era de origem lacónia ou lídia foi assunto muito contestado pelos estudiosos helenísticos, romanos e bizantinos. Veleio Patérculo (1.18.3) escreve Alcmana Lacones falso sibi uindicant, mas o dicionário enciclopédico Suda resolve a contenda a favor da naturalidade lacónia. Ora o moderno leitor anti-biografista não pode deixar de sentir um laivo de simpatia para com o epigramatista helenístico Antípatro de Tessalonica (Antologia Grega VII, 18) ${ }^{1}$, que desvaloriza o problema de se o poeta teria sido $\Lambda v \delta$ ò $\varsigma$

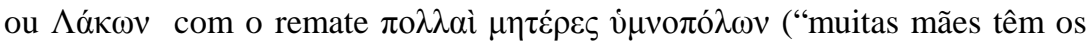
poetas”).

A lógica não permite que tomemos o fragmento $16 P M G$ como prova concludente nesta matéria, pois se, no poema (isto é, na sua já irrecuperável forma completa), o ỏví $\rho$ referido como sendo natural de Sárdis fosse o poeta, não se teria gerado a incerteza sobre a sua origem entre os seus leitores gregos mais tardios; temos, assim, de concluir que, nesse poema, o homem que "não era rústico nem inexperto" seria outro que não o autor:

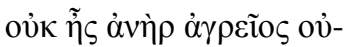

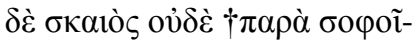

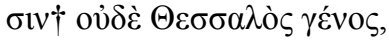

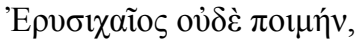

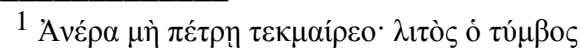

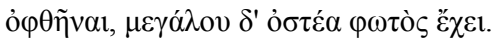

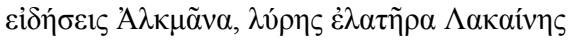

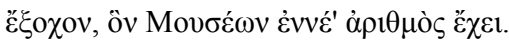

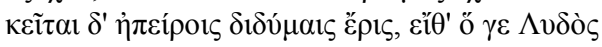

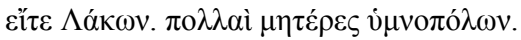

("Não julgues o homem pela lápide. O túmulo é pequeno / de ver, mas contém os ossos de um homem grande. / Nele verás Álcman, excelente dedilhador da lira lacónia, um dos Nove, número das Musas. / Jaz como disputa entre dois continentes, quer tenha sido lídio / ou lacónio. Muitas mães têm os poetas.”) 
$\dot{\alpha} \lambda \lambda \grave{\alpha} \Sigma \alpha \rho \delta i ́ \omega v \dot{\alpha} \pi^{\prime} \dot{\alpha} \kappa \rho \tilde{\alpha} v^{2}$.

Sobre a data de Álcman, as informações da Suda, ainda que aparentemente precisas, não merecem crédito devido aos erros históricos que encerram. Por meio da análise de dados internos, West chegou à conclusão de que Álcman deve ser situado nos últimos decénios do séc. VII a.C, talvez até no início do séc. VI (“Alcmanica”, pp. 188-194).

A data da morte de Álcman não é registada por nenhum comentador antigo, embora Aristóteles nos dê (certamente fantasiosa) informação sobre a causa do falecimento do poeta. Cito a História dos Animais (556b), na tradução de Maria de Fátima Sousa e Silva (Lisboa, 2006, pp. 245-6): “os piolhos nascem das carnes [...] Há certas pessoas que sofrem desta doença, quando têm uma humidade corporal elevada. Já houve casos de pessoas que pereceram com esta enfermidade, como o poeta Álcman, por exemplo”3.

Certo é, no entanto, que a actividade artística de Álcman se desenvolveu na Lacónia. Os antigos viam-no, de resto, como poeta que cultivou especialmente o dialecto da região. Segundo Pausânias (3.15.2: vol. I, p. 237, ed. Rocha Pereira), isso não desfeou a sua poesia, mau grado a intrínseca fealdade do dialecto lacónio (na opinião do Periegeta).

A Suda atribui a Álcman seis livros de poesia, de que chegaram até nós escassos fragmentos, transmitidos por papiros danificados ou citações em autores tardios. O título de uma das suas colectâneas, As Mergulhadoras (Ko $\lambda v \mu \beta \tilde{\omega} \sigma \alpha \imath)$ aguça-nos a curiosidade, mas nada sabemos quanto ao seu conteúdo.

2 Tradução portuguesa em Poesia Grega de Álcman a Teócrito, Lisboa, 2006, p. 19. A expressão entre cruces na edição dos $P M G$ de Page é interpretada por West (“Alcmanica”, Classical Quarterly 15 [1965], p. 188) como significando "in poetic circles”, achega que melhora a solução (meramente de compromisso) por mim encontrada.

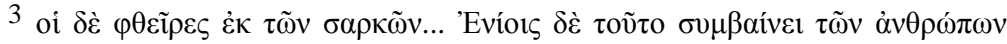

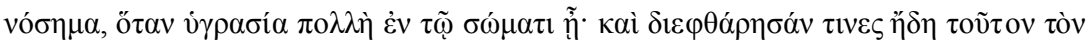

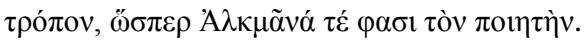




\section{O “Grande Partenéion"4}

O fragmento mais importante de Álcman é o "Grande Partenéion" transmitido por um papiro possivelmente do séc. I d.C. (actualmente no Louvre em Paris), encontrado numa sepultura em Saqqâra (Egipto) em 1855 e publicado pela primeira vez em 1863.

Trata-se de um poema composto para ser cantado por um coro de donzelas no decurso de um festival religioso. A primeira parte do poema, cujo teor parece ser mitológico, é quase impossível de reconstituir; ainda assim, descortinamos o que parece ser uma narração da vitória de Héracles sobre os filhos de Hipocoonte, narração que desagua numa $\gamma v \omega ́ \mu \eta$ memorável (após a asserção [vv. 34-35] de que os Hipocoôntidas sofreram trabalhos inesquecíveis por terem praticado o mal):

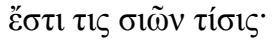

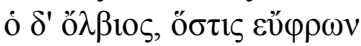

$$
\begin{aligned}
& \dot{\alpha} \mu \varepsilon \varepsilon^{\prime} \alpha v[\delta 1] \alpha \pi \lambda \varepsilon \varepsilon_{\kappa \varepsilon}
\end{aligned}
$$

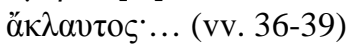

A parte legível do poema, que aparece de seguida, é, no mínimo, desconcertante. Como escreve Gloria Ferrari num brilhante estudo sobre o “Grande Partenéion” publicado em 20085,

for five of the eight partially preserved stanzas, representing half the estimated maximum length of the poem, the chorus gives what amounts to an ecphrasis of its own performance that repeatedly appeals to the sense of sight. Not only do the singers describe their own appearance and actions, but they emphatically point to what they see and turn to the audience with direct questions, eliciting ocular responses.

A frase crucial na citação acima transcrita parece-me ser a que aponta para os vv. 40-101 como écfrase da própria execução coral: como se as intervenientes no espectáculo coral se tivessem incumbido a si próprias de fazerem, “ao vivo”, em concomitância com a execução musical e

4 Tradução parcial de Maria Helena da Rocha Pereira em Hélade, Porto, 2003 p. 127; tradução completa (dos versos legíveis, entenda-se) em Poesia Grega de Álcman a Teócrito, pp. 15-17.

${ }^{5}$ G. Ferrari, Alcman and the Cosmos of Sparta, Chicago, 2008, p. 2. 
coreográfica, o respectivo relato. Assim sendo, o poema é ao mesmo tempo guião e espelho da execução coral; e o texto escrito é o próprio registo "audiovisual" do acontecimento. Sendo, cronologicamente, o primeiro grande trecho lírico que conhecemos da poesia ocidental, o "Grande Partenéion” de Álcman não deixa de ser de uma modernidade verdadeiramente assombrosa.

Na écfrase que o coro de donzelas nos dá da sua própria actuação, perpassam as rivalidades das raparigas e as paixonetas entre elas. Duas se destacam, mercê de uma beleza tão excepcional que atrai inevitavelmente o amor das outras: Ágido e Hagesícora. No decurso destes desabafos sentimentais, encontramos um dos muitos enigmas do poema: a identidade da figura chamada Enesímbrota, que Page interpretou como sendo a professora de dança cuja casa as jovens coreutas frequentariam ${ }^{6}$, ao passo que West optou antes pela interpretação de que Enesímbrota é perita em filtros de amor (cf. "Alcmanica”, p. 200). Se esta interpretação for a correcta, o "Grande Partenéion” surge-nos como um dos primeiros documentos poéticos de magia erótica na cultura grega.

Outro célebre problema, para o qual West oferece esclarecimento

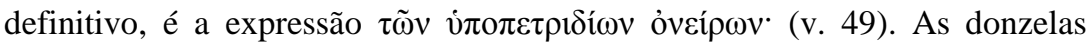
estão a falar de um cavalo forte, de cascos retumbantes, "dos que são avistados em sonhos sob os rochedos":

The equation $\dot{v} \pi \mathrm{o} \pi \varepsilon \tau \rho \dot{\delta} \delta 1 \mathrm{~s}=\dot{v} \pi$ ó $\pi \tau \varepsilon \rho \varsigma_{\zeta}$ is linguistically impossible. To talk of 'metathesis', or to conjure with a hypothetical intermediate vं $\pi$ o $\pi \varepsilon \tau \varepsilon \rho 1 \delta i ́ o v$, is to return to the philology of past ages. $\pi \varepsilon \tau \rho-$ means rock; and -í $\delta 10 \varsigma$ is characteristic of adjectives specifying a locality, as غ̇ंı

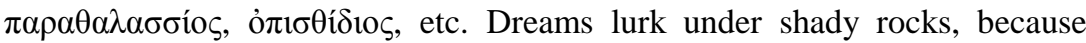
that, in the heat of midday, is where people sleep. (“Alcmanica”, p. 195)

Quantas estâncias o "Grande Partenéion” teria ao todo é questão que não podemos dilucidar com toda a certeza. Page e Robbins imaginam dez estâncias; Calame, apenas oito ${ }^{7}$. Independentemente do número total de estâncias, não há dificuldade em determinar a estrutura métrica

6 D. L. Page, Alcman: The Partheneion, Oxford, 1951, p. 46.

7 Cf. Page, Alcman: The Partheneion, p. 1-2; E. Robbins, "Alcman's Partheneion: Legend and Choral Ceremony”, Classical Quarterly 88 (1994), p. 7 ; C. Calame, Alcman, Roma, 1983, pp. 311-312. 
(monostrófica) da estância de catorze versos, ainda que o verso clausular da estância ( $\cup \cup-\cup \cup-\cup \mathrm{x}-$ ) escape às classificações tradicionais ${ }^{8}$ :

1. lecítio

2. hagesícoro ${ }^{9}$

3. lecítio

4. hagesícoro

5. lecítio

6. hagesícoro

7. lecítio

8. hagesícoro

9. trímetro trocaico

10. trímetro trocaico

11. dímetro trocaico

12. dímetro trocaico

13. tetrâmetro dactílico

14. verso aparentado com o decassílabo alcaico

Para finalizar esta breve nota de leitura, diremos que, apesar das inúmeras dificuldades de interpretação que o "Grande Partenéion” levanta, damos razão a esse sensível exegeta da poesia grega que foi Lesky, ao sugerir que elas "não nos privam do prazer que nos proporciona este trecho da mais bela poesia" 10 .

\section{FREDERICO LOURENÇO}

8 Sobre este verso, cuja segunda posição tanto surge ocupada por duas breves como por uma longa, e cuja penúltima posição é ancípite, G. O. Hutchinson comenta "the freedom at the end of the strophe is particularly remarkable: closes are commonly the strictest point in metre. In view of the lucid form of the rest, artistic audacity seems at least as likely an explanation as primitive imprecision” (Greek Lyric Poetry: A Commentary on Selected Larger Pieces, Oxford, 2001, p. 79).

9 O termo "hagesícoro" foi inventado por West (Greek Metre, Oxford, 1982) e designa um verso a que poderíamos também chamar "hiponacteu acéfalo”: $\mathrm{x}-\cup \cup$ $-\cup--$.

10 A. Lesky, História da Literatura Grega, Lisboa, 1995, p. 178. 